\title{
HOSPITAL DE SAN JOSÉ: ACREDITACIÓN DE ALTA CALIDAD
}

\author{
Luis Alberto Blanco R. MD*
}

En la Sociedad de Cirugía de Bogotá, Hospital de San José, nos encontramos muy complacidos porque tanto la Junta de Acreditación en Salud como el Consejo Directivo del ICONTEC nos aprobaron el otorgamiento del certificado de acreditación en la categoría de Institución acreditada en salud, por haber logrado las calificaciones necesarias por grupos de estándares. Contentos, por la importancia que representa el cumplimiento de este objetivo para el país, el sector de la salud, nuestra institución, para nosotros mismos como personas y por consiguiente para nuestros pacientes.

Muchos se preguntan ¿qué es en realidad la acreditación? El Sistema único de Acreditación es un componente del Sistema de Garantía de Calidad que se pone a disposición de los prestadores de servicios de salud, que en forma voluntaria quieran demostrar el cumplimiento de altos niveles de calidad, es decir por encima de las condiciones mínimas que establece el Sistema Único de Habilitación.

Estaba una tarde observando el diploma que nos entregaron como acreditados, cuando se me vino al pensamiento el recuerdo que en una pared de la austera casa del profesor Laurentino Muñoz, miembro de la Sociedad de Cirugía de Bogotá y humanista de tiempo completo, colgaba desde hacía mucho tiempo una inscripción de Eurípides grabada en barro. En ella se podía leer en griego milenario el siguiente lema: «No parecer sino ser». Me pregunté de inmediato: ¿por qué evoqué el recuerdo preciso cuando estaba mirando aquel diploma? Pensé que, tal vez, lo que quería transmitirnos el doctor Laurentino

* Director Médico, Sociedad de Cirugía, Hospital de San José, Bogotá DC, Colombia. con aquella inscripción era el concepto de que no debemos "parecer sino ser" y que la respuesta a mi pregunta estaba ahí. Caí en cuenta de que el trabajo para obtener la acreditación lo habíamos realizado de acuerdo con los lineamientos de aquel lema, es decir había sido realizado desde el ser, de una manera real y objetiva, para "que no pareciera sino que fuera". Considero importante este concepto filosófico traído del recuadro de la casa del doctor Laurentino, porque la acreditación podría ser tomada como el simple cumplimiento de un requisito para el cual se llenan unos papeles y se elabora un documento muy completo acerca de los avances en la gestión de calidad, pero de apariencia, sin tener en cuenta que los trabajadores de la salud llevan en lo más profundo de su ser el concepto real del cuidado de las personas.

Existe la famosa frase salomónica de la historia sagrada, venida al caso del mensaje del doctor Laurentino, que dice "La mujer del césar no solamente debe ser, sino parecer" con lo cual estoy de acuerdo. Pero ya desde la antigua Grecia se preguntaban muchos filósofos "somos lo que parecemos o parecemos lo que somos". Dicha distinción resulta baladí para muchos, pero dice Rousseau de ellos que viven de "la opinión de los demás" porque no conciben la diferencia entre ser y parecer. Por otro lado hay quienes se acogen al relativismo ético de los sofistas, el cual ha ganado hoy simpatizantes. Protágoras, por ejemplo, dice: "El hombre es la medida de todas las cosas; de las que son en tanto que son y de las que no son en tanto que no son". Es decir todas las cosas son relativas de acuerdo como se miren y de quien las mire (relativismo ético). Nosotros nos acogemos al justo medio y decimos que la calidad "no solo debe ser sino parecer". La acreditación debe ser un testimonio de que la garantía de calidad, es para la institución un principio filosófico ético y moral. 
Somos unos convencidos de este planteamiento y que además, sin lugar a dudas, en la práctica trae beneficios económicos para la institución, personales para nosotros y sobre todo, una real garantía para nuestros pacientes.

Trataré en forma breve de demostrar lo anterior tomando como ejemplo el tema apasionante de la seguridad del paciente con el siguiente argumento. Para el año 2000 se estableció que 96.000 pacientes morían al año por causa de los errores cometidos durante la atención, cifra superior a las muertes causadas por los accidentes automovilísticos y a las producidas por el sida. En el 2002 la Organización Mundial de la Salud (OMS) hizo un pronunciamiento acerca de la seguridad del paciente en el sentido de obligar a sus países afiliados a unirse para luchar y así erradicar los daños producidos a los pacientes como producto de la atención en salud. En 2007 se declaró la guerra a la infección nosocomial y se instauró el lavado de manos, que ya había sido utilizado en 1857 por Ignaz Semmelwiss para bajar la mortalidad de las puérperas del $9 \%$ al 3\%. En la última década con el advenimiento del movimiento global de la seguridad, estas infecciones no se llaman nosocomiales sino "asociadas con el cuidado de la salud", o sea que son inducidas por el deficiente cuidado de los pacientes y se trabaja para erradicarlas. Hoy las listas de chequeo son recomendadas al igual que en la aviación, como herramienta indispensable para gestionar el riesgo y prevenir los eventos adversos, materia en la cual se han realizado múltiples acciones. Recientemente, se destaca el acierto del Sistema único de Acreditación en salud en Colombia que incluyó el tema de seguridad del paciente como requisito fundamental para calificar la alta calidad en la prestación de los servicios. Todas estas actividades han llevado a que en el lapso de los últimos años, se haya reducido el número de muertes por errores médicos en $50 \%$.

Reconocemos que el comienzo del proceso de la acreditación es muy difícil para las instituciones, por ejemplo en lo que tiene que ver con la cultura del reporte de los incidentes, eventos adversos y complicaciones, pues con frecuencia se presta a confusiones con los términos y no se sabe qué reportar. Lo importante es comprender para qué sirve cada cosa, evidenciar que existen resultados positivos medidos con indicadores y poder desarrollar una autocrítica efectiva.

Unas felicitaciones muy grandes para todos los colaboradores de la institución por los avances en el sistema de gestión de calidad y el nivel demostrado en el cumplimiento de los estándares, lo cual implica importantes esfuerzos y compromisos con el hospital y con el sistema de acreditación. 